\title{
Teaching Challenges Using the Zoom Application that Focuses on Student Concentration in Online Classrooms
}

\author{
Schruck Gillantes ${ }^{1}$, Stephan Yreck $^{1}$ \\ ${ }^{1}$ Faculty of Education, University of the Philippines Diliman, Philippines \\ Received: March 11, 2021 \\ Revised: April 21, 2021 \\ Accepted: May 8, 2021
}

\begin{abstract}
The fast advancement in information technology stimulates educational creativity as well. Learning and training practices are often not only carried sout in the traditional manner, but also with the usage of a multitude of learning technologies options. The zoom program is one of the learning resources used in online courses. Zoom was an application developed during the Covid-19 timeframe to address the limitations between educators and students, especially in terms of space and time. With E-learning, educators and students are not limited to one dimension of time and space, and learning will run and neglect both. Learning by simulated children's attention, on the other hand, causes disruption in the learning phase. During the learning phase, students must maintain a high level of concentration. The level of concentration of students has a significant impact on the learning process' outcomes. Since attitude and focus have a beneficial association, high focus may often affect a person's attitude in a learning phase in order to produce optimal performance. Many factors may affect a person's attention, one of which is the learning environment. A peaceful atmosphere can undoubtedly improve a person's concentration level, while a silent / noisy environment will exacerbate one's focus during the learning phase.
\end{abstract}

Keywords: Online Learning, Zoom Application, Student Construction

\section{Introduction}

It has had its own effects on the field of education in the wake of the Covid-19 virus epidemic that occurred in Indonesia. Several policies or actions that can be taken by the government during the corona virus pandemic have been released by the government. One of the measures implemented was the cancellation of all training and learning programs, which were then replaced with an online framework or online. The detection and treatment of the corona virus disease (Covid-19) necessitates the use of online learning in educational institutions. Students may meet with lecturers at any time by online or distance learning. Of the same way, vice versa. Contact may be exclusive to one student and one professor, or it can be open to all students with a bulletin board. Communication, whether simultaneous or not, may also be chosen. Distance learning, in legal terms, is a learning pattern in which instructors and pupils are separated. Distance education is a form of education in which students are isolated from their teachers and learn through the use of computers, correspondence, and other media (Threlkeld \& Brzoska, 1994; Anderson, 2003; Simonson et al., 2019).

E-learning is another term for distance education. E-learning is a program designed to address the barriers that exist between educators and students, namely in terms of space and time. Through E-learning, educators and students are not limited to one dimension of space and time, and learning may take place by ignoring all of these factors. Distance learning approaches should be applied to all four aspects of schooling: general education, improving educators' content skills, teaching pedagogy and infant growth, and as a guide to better classrooms. Students may be familiar with online learning. Students may now research entirely remotely while also socializing with peers, studying during classes, and engaging in current subject- 
specific debates, thanks to technological advancements. Video conferencing, notes, multimedia, and other methods are used. As a result, lecture operations can continue, and downloadable or online lectures can be viewed from anywhere at some period that has been agreed upon.

\section{The Definition of Online Learning}

The rapid development of Information Technology also encourages an innovation in the world of education. Learning and teaching activities are now not only carried out conventionally, with a variety of learning technology choices that can be used as an alternative to learning. Through computers, the learning presented will be more interesting, interactive and can be done independently. The use of the internet as a learning medium positions students to be able to learn independently. Through the internet, students can access online references from various libraries, encyclopedias and various other online learning sites.

With the internet, access to information can be done anywhere and anytime without being bound by time and space. Some of the uses of internet technology in learning activities are elearning and online learning (McGreal \& Elliott, 2008; Anohina, 2005; Moore et al., 2011). Both use the internet in its application so that students can learn anytime and anywhere independently. With the internet, learning can also be done together like learning in a real class. Learning like this is called a virtual classroom, students interact with the teacher through a camera on a computer that is connected to the internet network. Teachers do not need to be physically present in class, because students can study teaching materials and do learning assignments and exams by accessing computer networks that have been prepared online. Besides that, students can also interact with other students to discuss via email, chat and so on. Learning with e-Learning can be delivered in a synchrounous manner, which is where learning is carried out immediately, or asynchronously, that is, learning is carried out at different times. An example of e-Learning synchronously is learning via webcam between teachers and students live on the spot. Meanwhile, an example of asynchronous delivery is that the teacher first makes learning material or videos, then the material or video is uploaded before the lesson will take place. The learning material presented in e-Learning is in the form of text, graphics, animation, simulation, audio, and video. E-Learning must also have features for discussion such as chatting.

\section{Characteristics of Online Learning}

The following are the characteristics of e-Learning: (1) The ability of students to capture learning materials does not depend on the instructor / teacher, because students construct their own knowledge through teaching materials that are delivered through the website interface; (2) Sources of knowledge are scattered everywhere and can be accessed easily by everyone. This is due to the global nature of the Internet's media and accessible to anyone connected to it; (3) Teachers / educational institutions function as mediators / guides; (4) A restructuring of the education system, curriculum and management policies is needed that can support the optimal use of Information and Communication Technology for education.

The four characteristics above are what distinguish e-learning from conventional learning activities. In e-learning, students' capture of learning material is no longer dependent on the instructor / teacher, because students build their own knowledge through teaching materials delivered through the e-learning application. In e-learning too, sources of knowledge are scattered everywhere and can be accessed easily by everyone.

\section{Advantages of Online Learning}

Benefits of Online Education Any of the benefits of distance learning was identified by students. We looked through a total of 120 comments. With 31.01 percent of responses, the most popular benefit for online learning was a convenient instructional atmosphere. Student 
comments were identical to what they could listen to at home; they were not restricted by place, could listen anywhere, wherever, and were not restricted by time or space when clustered into a pleasant educational setting theme. The most common trend was time management, which came in second with an answer rate of 26.98 percent. They do not waste travel time, their travel time is preserved, and the travel time load has been minimized, to name a few examples of responses classified under this theme. A strong response rate of 20.95 percent is also shown by smooth conversation. They will talk comfortably during the conversation, and they can more readily pose questions to the instructor, as an illustration of the answers grouped into this theme. They have the impression of being in a one-on-one lesson, and the conversation seems to be smooth; they can pose questions more quickly than in traditional lectures. Another significant benefit of reused data is that it may be used to reduce shipping costs. The benefits of online learning include having ample time, having a lot of spare time, and saving money on transportation, whilst the drawbacks include unclear content distribution, frustration and a monotonous environment, and a lack of student contact with the instructor. The benefits of online learning include having flexible time, having plenty of spare time, and saving money on transportation, whilst the drawbacks include unclear content distribution and a lack of studentteacher contact. The benefits of online learning include having flexible time, having plenty of spare time, and saving money on transportation, whilst the drawbacks include unclear content distribution and a lack of student-teacher contact.

\section{Disadvantages of Online Learning}

Distance learning's drawbacks Regarding concerns about distance learning, a total of 120 responses were recorded (Naik et al., 2021; Wang et al., 2009). The most common criticism was network instability, which accounted for 38.34 percent of all complaints. Delays are common, teachers' voices and instructional resources are not synchronous, and they can't take lessons while wi-fi isn't attached, according to certain common opinions regarding network volatility. Unilateral interaction was the second most common concern, with an 18.31 percent response rate. Interaction is impossible, and the instructional atmosphere is of low quality; content is not adequately communicated, and direct interaction is impossible. A popular response is for teachers to make improvements without interacting with students. Reduced concentration was the third most common concern, accounting for 23.13 percent of responses. Many students stated that staying focused in class for extended stretches of time was challenging. Insufficient data provision, dissatisfaction with assignment changes, constraints on team projects, reduced academic performance, unprepared class design, reduced class understanding, dissatisfaction with class, class dissatisfaction, grading, administrative dissatisfaction, dissatisfaction with relationship formation, and dissatisfaction with relationship formation were among the other themes identified in the dissatisfaction response. The benefits of online learning include having ample time, having a lot of spare time, and saving money on transportation, whilst the drawbacks include unclear content distribution, frustration and a monotonous environment, and a lack of student contact with the instructor. The benefits of online learning include having flexible time, having plenty of spare time, and saving money on transportation, whilst the drawbacks include unclear content distribution and a lack of studentteacher contact (Oblinger et al., 2001; Wang, 2012). The benefits of online learning include having flexible time, having plenty of spare time, and saving money on transportation, whilst the drawbacks include unclear content distribution and a lack of student-teacher contact.

\section{The Importance of Student Concentration in Learning}

Students' focus and desire to learn are very important in the learning phase, because the higher their concentration and motivation, the stronger their learning results would be. Learning is an action that is done intentionally with the intention of achieving a target. One of the most significant diverse factors is the inspiration learning mechanism. Students who underachieve 
always do so not because of a lack of talent, but rather because they lack desire to learn and therefore do not attempt to guide all of their skills. The motivating aspects of the conventional learning method, which employs an expository technique, are often overlooked by the instructor. The instructor seems to compel his pupils to consider the information he provides. This condition is unfavorable when students are unable to perform to their full potential, resulting in poor learning results. Motivation is central to the current understanding of the learning process.

\section{In Online Schooling, Students Have Difficulty Concentrating}

Learning emphasis is the focus of interest during the course of modifying behaviour, and may be expressed as ability, use, assessment, or in relation to behavior and beliefs, information, and essential skills in a variety of fields of study. During the learning phase, students must maintain a high level of concentration. The level of concentration of students has a significant impact on the learning process' outcomes. Since attitude and focus have a beneficial association, high focus may often affect a person's attitude in a learning phase in order to produce optimal performance. Many factors may affect a person's attention, one of which is the learning environment. A peaceful atmosphere can undoubtedly improve a person's concentration level, while a silent / noisy environment will exacerbate one's focus during the learning phase. According to environmental science, it has a major impact on one's absorption level. Any learning process necessitates a high level of concentration. This is because focus is a factor that helps students understand. If students are unable to focus on the current class, the effect on the students would be negative and they would not benefit from the lesson. Because of the value of focus for pupils, it may be a requirement for students to study in order to meet their academic objectives. The desire to concentrate on the lesson is known as mindfulness. The emphasis of interest is on the learning material's content and the method of acquiring it. Concentration of school is one of the social facets of learning that is sometimes overlooked by others who are not learning. This is because what is observed by a person's behavior may not often correspond to what the individual is really thinking. The capacity of and student's brain to concentrate on what is being taught has an effect on their learning concentration. This focus on detail increases the probability that students can learn and comprehend the details presented.

\section{Conclusion}

Students and instructors will benefit from online learning, but there will still be drawbacks. One of the benefits that can be gained is the ability to practice at your own pace. The disadvantage for students is that they find it challenging to focus in class due to many disruptions at home or network issues, and they will feel sleepy if there is little direct contact in the classroom. As a result, students may become bored and find it difficult to concentrate on studying. The level of concentration of students has a significant impact on the learning process' outcomes. Since attitude and focus have a beneficial association, high focus may often affect a person's attitude in a learning phase in order to produce optimal performance. Many factors may affect a person's attention, one of which is the learning environment.

\section{References}

Anderson, T. (2003). Modes of interaction in distance education: Recent developments and research questions. Handbook of distance education, 129-144.

Anohina, A. (2005). Analysis of the terminology used in the field of virtual learning. Journal of Educational Technology \& Society, 8(3), 91-102.

McGreal, R., \& Elliott, M. (2008). Technologies of online learning (e-learning). Theory and practice of online learning, 115. 
Moore, J. L., Dickson-Deane, C., \& Galyen, K. (2011). e-Learning, online learning, and distance learning environments: Are they the same?. The Internet and Higher Education, 14(2), 129-135.

Naik, G. L., Deshpande, M., Shivananda, D. C., Ajey, C. P., \& Manjunath Patel, G. C. (2021). Online Teaching and Learning of Higher Education in India during COVID-19 Emergency Lockdown. Pedagogical Research, 6(1).

Oblinger, D., Barone, C. A., \& Hawkins, B. L. (2001). Distributed education and its challenges: An overview (Vol. 1). Washington, DC: American Council on Education.

Simonson, M., Zvacek, S. M., \& Smaldino, S. (2019). Teaching and Learning at a Distance: Foundations of Distance Education 7th Edition.

Threlkeld, R., \& Brzoska, K. (1994). Research in distance education. Distance education: Strategies and tools, 41-66.

Wang, M., Shen, R., Novak, D., \& Pan, X. (2009). The impact of mobile learning on students' learning behaviours and performance: Report from a large blended classroom. British Journal of Educational Technology, 40(4), 673-695.

Wang, Y. (2012). Education in a changing world: Flexibility, skills, and employability. World Bank. 